\title{
(6) OPEN ACCESS \\ Effectiveness of breed-specific legislation in decreasing the incidence of dog-bite injury hospitalisations in people in the Canadian province of Manitoba
}

\author{
Malathi Raghavan, ${ }^{1,2}$ Patricia J Martens, ${ }^{1,3}$ Dan Chateau, ${ }^{1,3}$ Charles Burchill ${ }^{3}$
}

- Additional figures and tables are published online only. To view these files please visit the journal online (http://dx.doi.org/ 10.1136/injuryprev-2012040389).

${ }^{1}$ Department of Community Health Sciences, Faculty of Medicine, University of

Manitoba, Winnipeg, Manitoba, Canada

${ }^{2}$ Undergraduate Medical Education, Faculty of Medicine, University of Manitoba, Winnipeg, Manitoba, Canada ${ }^{3}$ Manitoba Centre for Health Policy, University of Manitoba, Winnipeg, Manitoba, Canada

\section{Correspondence to}

Dr Malathi Raghavan, 260-727 McDermot Avenue, Winnipeg, Manitoba R3E 3P5, Canada; malathi.raghavan@med. umanitoba.ca

Accepted 4 June 2012

Published Online First 1 August 2012

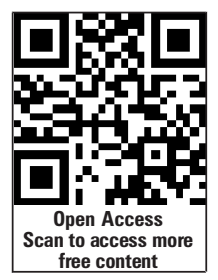

\section{ABSTRACT}

Background The city of Winnipeg was the first among several jurisdictions in Manitoba, Canada, to introduce breed specific legislation (BSL) by banning pit-bull type dogs in 1990. The objective of the present work was to study the effectiveness of BSL in Manitoba.

Methods Temporal differences in incidence of dog-bite injury hospitalisations (DBIH) within and across Manitoba jurisdictions with and without BSL were compared. Incidence was calculated as the number of unique cases of $\mathrm{DBIH}$ divided by the total person-years at risk and expressed as the number per 100000 person-years. Year of implementation determined the pre-BSL and post-BSL period for jurisdictions with BSL; for jurisdictions without BSL to date, the entire study period (1984-2006) was considered as the preimplementation period. The annual number of $\mathrm{DBIH}$, adjusted for total population at risk, was modelled in a negative binomial regression analysis with repeated measures. Year, jurisdiction and BSL implementation were independent variables. An interaction term between jurisdiction and BSL was introduced.

Results A total of 16 urban and rural jurisdictions with pit-bull bans were identified. At the provincial level, there was a significant reduction in $\mathrm{DBIH}$ rates from the preBSL to post-BSL period (3.47 (95\% Cl 3.17 to 3.77$)$ per 100000 person-years to $2.84(95 \% \mathrm{Cl} 2.53$ to 3.15$)$; $\mathrm{p}=0.005)$. In regression restricted to two urban jurisdictions, DBIH rate in Winnipeg relative to Brandon (a city without BSL) was significantly $(p<0.001)$ lower after BSL (rate ratio $(\mathrm{RR})=1.10$ in people of all ages and 0.92 in those aged $<20$ years) than before $(R R=1.29$ and 1.28 , respectively).

Conclusions BSL may have resulted in a reduction of $\mathrm{DBIH}$ in Winnipeg, and appeared more effective in protecting those aged $<20$ years.

Dog-bite injuries are, to an extent, a preventable cause of injuries in people, especially children. ${ }^{1-4}$ To reduce the frequency of occurrence of this multifactorial public health issue, regulatory measures such as dog-control legislation are sometimes introduced. ${ }^{5-8}$

Breed-specific legislation (BSL) is usually a law or ordinance pertaining to a specific breed of dogs such as pit-bull type dogs. ${ }^{7}$ There are two general forms of BSL: specific restrictions and outright bans. ${ }^{9}$ Past evaluations of different forms of regulations have led to conclusions that BSL is ineffective in reducing dog-bite injuries of varying severities. ${ }^{10-14}$ However, methodological shortcomings such as short-term observational periods or analysis of cross-sectional data limit the usefulness of inferences made from these studies and necessitate further assessment of population-level outcomes using stronger observational study designs that take into account period and cohort effects. A longer-term, population-level descriptive Catalonian study demonstrated a decline in dog-bite injury hospitalisations (DBIH) over a 12-year period as a result of stricter government regulations on potentially dangerous dogs and dog breeds. ${ }^{15}$

In 1990, Winnipeg, the capital city of the Canadian province of Manitoba, was the first major jurisdiction among several Canadian and international jurisdictions to implement BSL by banning pit-bull (terrier) type dogs from the city. 516 'Pitbull' was defined as covering pit bull terriers, Staffordshire bull terriers, American Staffordshire terriers, American pit bull terriers or any dogs with the appearance and physical characteristics predominantly conforming to the standards for any of the above breeds. ${ }^{16}$ The rural municipality (RM) of Macdonald followed with a similar ban of its own in 1992, while the northern city of Thompson restricted pit-bull type dogs in 1994. ${ }^{5} 1718$ The lack of a province-wide legislation afforded a unique opportunity to compare temporal differences in trends in DBIH within and across specific Manitoba jurisdictions.

Bites from pit-bull type dogs are thought to be more often associated with fatal or serious injuries as a consequence of their size, build and musculature. $^{3}{ }^{19-21}$ At a level 1 trauma centre in Texas, USA, people attacked by pit-bull dogs were associated with significantly higher Injury Severity Scores, poorer Glasgow Coma Scale scores, higher hospital charges and higher risk of death compared with people attacked by other dog breeds. ${ }^{21}$ Assuming that serious, non-fatal dog-bite injuries were more likely to be hospitalised, we hypothesised that frequency of DBIH gradually decreased with the implementation of a 'pit-bull' BSL. For study purposes, implementation was defined as introduction of legislation or by-law on paper. Bylaw enforcement was not measured or assessed. Since being bitten or injured by a dog (among other terrestrial mammals) continues to be cause for seeking rabies post-exposure prophylaxis (PEP), ${ }^{22-26}$ we also studied the effectiveness of BSL in decreasing the frequency of PEP in Manitoba, and compared and contrasted the patterns between $\mathrm{DBIH}$ and PEP in Manitoba. As PEP is administered 
for dog bites of all severities from unknown or unvaccinated dogs and for bites from other mammals, we hypothesised that BSL would have little effect, if any, on trends in PEP. As children are more likely to be victims of dog attacks, and legislation is usually recommended to protect children from dog-bite injuries, ${ }^{2} 8$ we hypothesised that fewer children will be hospitalised for dog-bite injuries in jurisdictions with BSL.

Therefore, the primary objective of the present study was to determine the incidence of DBIH over time for jurisdictions with and without BSL in Manitoba. The secondary objectives of the study were to report, for jurisdictions with and without BSL, trends in PEP and trends in age at DBIH and PEP.

\section{METHODS}

Apart from Winnipeg, Macdonald and Thompson, 16 additional jurisdictions with some form of a pit-bull clause were further identified by: (1) contacting the Association of Manitoba Municipalities (AMM); (2) individually emailing or telephoning 203 member municipalities of the AMM and receiving responses from 80 (39.4\%) of those contacted; (3) conducting an internetbased search for municipal-level animal control or dog-control by-laws with pit-bull specific text; and, (4) verifying the text of the local animal-control or dog-control by-laws for the 15 largest non-responding municipalities of Manitoba (by population numbers). That is, 19 municipalities with pit-bull BSL were identified and classified into 1 of 2 types of jurisdiction under study: those with a form of ban against pit-bull type dogs and those without a ban. The former jurisdictions contained words and phrases such as 'banned', 'prohibited', 'restricted animal', or 'no person shall harbour or keep' in their by-laws. In all, 16 such jurisdictions were identified and considered together as jurisdictions with BSL or 'experimental' jurisdictions (table 1; see also additional figure 1 available online). Breed-specific language did not necessarily exclude restrictive language regarding other dangerous dogs. The remaining three jurisdictions not included in the 'experimental' list were: (1) the town of Hartney (population: 400) as a pit-bull specific ban was implemented first in the year 2007, the year after the period under study; (2) the RM of Coldwell and (3) the RM of Mountain, as they merely imposed restrictions such as high license fees on owners

Table 1 Jurisdictions that implemented 'pit-bull' bans in Manitoba during the years 1984-2006

\begin{tabular}{lcl}
\hline $\begin{array}{l}\text { Name of jurisdiction } \\
\text { (category) }\end{array}$ & $\begin{array}{l}\text { Total number of } \\
\text { person-years at } \\
\text { risk during study period }\end{array}$ & $\begin{array}{l}\text { Year of } \\
\text { implementation } \\
\text { of 'pit-bull' specific ban }\end{array}$ \\
\hline Winnipeg (city) & 14684956 & 1990 \\
Steinbach (city) & 266980 & 1991 \\
Niverville (town) & 45515 & 1991 \\
Cartier (RM) & 65722 & 1991 \\
MacDonald (RM) & 107234 & 1992 \\
Thompson (city) & 343487 & 1994 \\
Beausejour (town) & 79511 & 1996 \\
Selkirk (city) & 225355 & 2001 \\
McCreary (village) & 13319 & 2001 \\
West St. Paul (RM) & 72625 & 2002 \\
De Salaberry (RM) & 59955 & 2002 \\
St. François Xavier (RM) & 19632 & 2003 \\
Minitonas (town) & 13860 & 2003 \\
Plum Coulee (town) & 24239 & 2004 \\
The Pas (town) & 209769 & 2005 \\
Crystal City (village) & 10339 & 2006 \\
\hline RM, rural munipality & &
\end{tabular}

$\mathrm{RM}$, rural municipality. of pit-bull type dogs and not outright bans. These three jurisdictions along with all remaining Manitoba municipalities were considered together as jurisdictions without BSL or 'control' jurisdictions for study purposes. Winnipeg and Brandon, the second largest city in Manitoba, were the only jurisdictions considered urban; all other Manitoba jurisdictions were defined as rural. ${ }^{27}$

Hospitalisation and PEP data were extracted for all postal code regions of Manitoba from administrative health databases in the Population Health Research Data Repository housed at the Manitoba Centre for Health Policy (MCHP). ${ }^{28}$ This repository contains deidentified but person-level medical records for virtually all of Manitoba's residents, linkable across records and across time through an encrypted health number.

All-cause hospitalisations from year 1984/85 are contained in the Hospital Separation Abstracts Database. This database, which contains inpatient and outpatient admissions to hospitals, was searched for DBIHs from 1984/85 through 2006/07. Dog-bite injuries were identified by the International Classification of Diseases, 9th edition, Clinical Modification (ICD-9-CM) code E906.0 and the ICD-10 Canada (ICD-10-CA) code W54. ${ }^{29}$

'Physician billing claims' in the Medical Services Database and The Manitoba Immunisation Monitoring System (1984/ 85-2006/07) (MIMS) were searched to identify rabies postexposure vaccine tariff codes, given as AB-Post Rabies Vaccine 8751 and IG-Rabies Immune Globulin 8768. Tariff codes from the past $(8752$, 8753, 8754, 8755) for Rabies Inactive Human Diploid Vac (Post Exposure) second to fifth dose (INIT series) were also identified for analysis. Diagnostic codes available in physician billing claims were searched to report on the various indications leading to PEP. Children's vaccinations were more likely to be recorded in MIMS. However, MIMS did not contain diagnostic codes.

All three databases are encounter-based databases that capture each encounter or billing arising per person on a separate row in the database. To eliminate potential duplicate hospitalisations or PEP series administrations for the same injury, only the first $\mathrm{DBIH}$ and first encounter for PEP per unique individual occurring in a month's time was analysed.

Using postal codes derived from residential addresses of individuals requiring hospitalisations or $\mathrm{PEP}$, the number of unique hospitalisations and PEP series administrations were summarised by year and jurisdiction and used as numerator data while calculating incidence. The population database was accessed to provide population counts for years 1984-2006. Population counts were summarised by year and jurisdiction to provide denominator data for incidence. Each person under study for 1 year contributed 1 person-year to the study. Incidence was defined as the number of cases, whether DBIH or PEP, in a specified time period, divided by the total person-years at risk during that period, and expressed as the number per 100000 person-years. ${ }^{30}$ The $95 \%$ CIs were calculated using the approach for Poisson distribution. ${ }^{31} 32$

Year of BSL implementation was used to determine pre-BSL and post-BSL period for jurisdictions with BSL (table 1). For all other jurisdictions without BSL to date, the entire study period (1984-2006) was considered as preimplementation period in a quasiexperimental manner. ${ }^{33-35}$ Age at DBIH and PEP were compared between pre-BSL and post-BSL periods using the non-parametric Wilcoxon rank sum test and the $\chi^{2}$ test.

The annual number of cases of DBIH or PEP that occurred in a jurisdiction, adjusted for total population at risk, was modelled using a negative binomial regression (NBR) with jurisdiction as a repeated subject (generalised estimating equations). ${ }^{36-40}$ These 
NBR models provide regression coefficients ' $\beta$ ', which when exponentiated are the rate ratios (RRs). ${ }^{41} 42$ The $R R$ indicates the magnitude of difference in rate of outcomes associated with each unit increase in explanatory variable when all other variables are held constant. Time (calendar year), place (jurisdiction with or without BSL; urban or rural jurisdiction) and intervention (ie, whether BSL in effect or not in calendar year) were entered as the independent variables. ${ }^{43}$ As legislation is nonrandom and may represent localised conditions and necessities, an interaction term between jurisdiction and intervention was introduced. A negative $\beta$ associated with the interaction term was expected if implementation of BSL was hypothesised to decrease incidence. Because of the presence of the interaction term, $\beta$ associated with jurisdiction alone represents the preintervention effect due to jurisdiction. To get the postintervention effect associated with jurisdiction, the $\beta$ associated with interaction term was added to the preintervention effect by using an estimate statement. ${ }^{43}$

Data were accessed at MCHP and analysed using SAS V.9.2 in a windowing environment (SAS, Cary, North Carolina, USA). ${ }^{44}$ The study was approved by the University of Manitoba Health Research Ethics Board and by Manitoba's Health Information Privacy Committee (HIPC). Due to HIPC concerns regarding privacy and confidentiality, case counts $<6$ are not reported in this study (unless they are 0 ). As the number of cases of DBIH and PEP were small in several jurisdictions, only aggregated data are reported. Data for the two largest urban centres of Manitoba (the Cities of Winnipeg and Brandon) and two northern midsized towns (The Pas and the Town of Flin Flon) are presented individually in the descriptive tables so that incidence can be compared between similar jurisdictions with and without BSL. Brandon has had dangerous dog legislation without any breed references since $1994 .{ }^{45}$

\section{RESULTS}

\section{Description of cases of DBIH}

In the years 1984-2006, 838 unique dog-bite injuries in 830 individuals required hospitalisations in Manitoba. That is, 822 individuals were hospitalised once and 8 individuals were hospitalised twice. The median (minimum, maximum) time period between the first and second hospitalisations in these eight individuals was 11.5 months (1 month, 39 months). Among 838 DBIHs, 721 (86\%) required an overnight stay; the median (maximum) number of days of hospital stay for these 721 hospitalisations was 3 (75). A total of 467 (55.7\%) of the hospitalised individuals were male. The city of Winnipeg, the largest jurisdiction had the highest number of DBIHs (table 2).

\section{Description of cases of rabies PEP}

During the study period, PEP series were initiated or completed in 1903 individuals (table 2); 518 individuals were identified through the physician billing claims; 553 through MIMS; 832 were identified through both databases. A total of $982(51.6 \%)$ PEP initiations were in males. Most common diagnostic codes accompanying first encounter for PEP and captured in physician billing claims were: contact with or exposure to communicable disease 'V01' (43.4\%); need prophylactic vaccine certain viral disease 'V04' (10.4\%); open wound other and unspecified site no limbs '879' (10.1\%); open wound hand except finger alone '882' $(2.7 \%)$.

In jurisdictions with BSL, there were no significant differences in incidence of DBIH between pre-BSL and post-BSL implementation (table 3). However, statistically significant differences were observed at the provincial level when comparing across Manitoba jurisdictions with and without BSL in a quasiexperimental manner (percentage change in incidence was -18.1\%). Despite a trend to suggest a post-BSL lag effect in Winnipeg, no significant differences were observed in DBIH rates in Winnipeg relative to Brandon (see additional figure 2 available online). The incidence of PEP increased significantly in jurisdictions with BSL with the exception of The Pas (see supplementary table 1, available online). However, incidence of PEP increased in all of Manitoba and as such its increase was relatively low in jurisdictions with BSL.

With the exception of the very young ( 0 to $<2$ years old), it appeared that those aged $<20$ years were less likely to be hospitalised due to dog-bite injuries or to receive PEP in Manitoba post-BSL compared with pre-BSL implementation (see supplementary table 2, available online). The median (minimum, maximum) age at DBIH in post-BSL Manitoba was

Table 2 Description of study population in the years 1984-2006

\begin{tabular}{|c|c|c|c|c|c|c|c|}
\hline & \multicolumn{7}{|l|}{ Years 1984-2006 } \\
\hline & \multirow[b]{2}{*}{$\begin{array}{l}\text { Total number } \\
\text { of person-years } \\
\text { at risk }\end{array}$} & \multicolumn{3}{|c|}{ Dog-bite injury hospitalisations } & \multicolumn{3}{|c|}{ Rabies post-exposure prophylaxis } \\
\hline & & $\begin{array}{l}\text { Total } \\
\text { number }\end{array}$ & $\begin{array}{l}\text { Average } \\
\text { number } \\
\text { per year }\end{array}$ & $\begin{array}{l}\text { Incidence }\left(95 \% \mathrm{Cl}^{*}\right) \\
\text { per } 100000 \\
\text { person-years }\end{array}$ & $\begin{array}{l}\text { Total } \\
\text { number }\end{array}$ & $\begin{array}{l}\text { Average } \\
\text { number } \\
\text { per year }\end{array}$ & $\begin{array}{l}\text { Incidence }\left(95 \% \mathrm{Cl}^{*}\right) \\
\text { per } 100000 \\
\text { person-years }\end{array}$ \\
\hline All Manitoba jurisdictions & 26266540 & 838 & 36.4 & $3.19(2.97$ to 3.41$)$ & 1903 & 82.7 & $7.24(6.92$ to 7.57$)$ \\
\hline $\begin{array}{l}\text { All jurisdictions that did not implement } \\
\text { BSL in the years } 1984-2006\end{array}$ & 10024042 & 363 & 15.8 & $3.62(3.25$ to 3.99$) \dagger$ & 1208 & 52.5 & $12.05(11.37$ to 12.73$) \neq$ \\
\hline City of Brandon & 960636 & 24 & 1.0 & $2.50(1.60$ to 3.72$) \S$ & 48 & 2.1 & 4.99 (3.68 to 6.62$) \Phi$ \\
\hline Town of Flin Flon & 165195 & 7 & 0.3 & $4.24(1.70$ to 8.73$) * *$ & Not reported & Not reported & $2.42(0.66$ to 6.20$) \dagger \dagger$ \\
\hline $\begin{array}{l}\text { All jurisdictions that implemented } \\
\text { BSL sometime during years } 1984-2006 \neq \ddagger\end{array}$ & 16242498 & 475 & 20.6 & $2.92(2.66$ to 3.19$) \dagger$ & 695 & 30.2 & $4.28(3.96$ to 4.60$) \neq$ \\
\hline City of Winnipeg & 14684956 & 417 & 18.1 & $2.84(2.57$ to 3.11$) \S$ & 554 & 24.1 & 3.77 (3.46 to 4.09$) 9$ \\
\hline The Pas & 206769 & 12 & 0.5 & $5.72(2.95$ to 9.99$) * *$ & 12 & 0.5 & $5.72(2.96$ to 9.99$) \dagger \dagger$ \\
\hline
\end{tabular}

*95\% Poisson $\mathrm{Cl}$

†Different at $p$ value $=0.002$.

$\neq$ Different at $p$ value $<0.0001$

§Different at $p$ value $=0.542$.

ๆDifferent at $p$ value $=0.062$.

**Different at $p$ value $=0.528$

+ Different at $p$ value $=0.136$

$\ddagger \ddagger$ Includes 16 jurisdictions with 'pit-bull' specific ban listed in table 1 .

$\mathrm{BSL}$, breed-specific legislation. 
Table 3 Incidence of hospitalised cases of dog-bite injuries in the preimplementation and postimplementation period of BSL in the province of Manitoba

\begin{tabular}{|c|c|c|c|c|c|}
\hline & Preimple & tation period of $\mathrm{BSL}^{*}$ & Postimpl & ntation period of $\mathrm{BSL}$ & p Value of difference \\
\hline & $\begin{array}{l}\text { Total } \\
\text { number }\end{array}$ & $\begin{array}{l}\text { Incidence }(95 \% \mathrm{Cl} \dagger) \\
\text { per } 100000 \text { person-years }\end{array}$ & $\begin{array}{l}\text { Total } \\
\text { number }\end{array}$ & $\begin{array}{l}\text { Incidence }(95 \% \mathrm{Cl} \dagger) \\
\text { per } 100000 \text { person-years }\end{array}$ & $\begin{array}{l}\text { preimplementation and } \\
\text { postimplementation periods }\end{array}$ \\
\hline All Manitoba jurisdictions & $507 \ddagger$ & $3.47(3.17$ to 3.77$) \S$ & 331 & $2.84(2.53$ to 3.15$) \S$ & 0.005 \\
\hline $\begin{array}{l}\text { All jurisdictions that did not implement } \\
\text { BSL in the years } 1984-2006\end{array}$ & 363 & $3.62(3.25$ to 3.99$) \uparrow * *$ & NA & NA & NA \\
\hline City of Brandon & 24 & $2.50(1.61$ to 3.72$) \dagger \dagger \neq \ddagger$ & NA & NA & NA \\
\hline Town of Flin Flon & 7 & $4.24(1.70$ to 8.73$) \S \S$ ब & NA & NA & NA \\
\hline $\begin{array}{l}\text { All jurisdictions that implemented } \\
\text { BSL sometime during years } 1984-2006^{* * *}\end{array}$ & 144 & $3.14(2.65$ to 3.69$) 9$ & 331 & $2.84(2.53 \text { to } 3.15)^{* *}$ & 0.319 \\
\hline City of Winnipeg & 110 & $2.93(2.41$ to 3.53$) \dagger \dagger$ & 307 & $2.81(2.49$ to 3.12$) \neq \ddagger$ & 0.697 \\
\hline The Pas & 12 & $6.21(3.21$ to 10.85$) \S \S$ & 0 & $0.00(0.00$ to 22.30$)$ ब & 0.999 \\
\hline
\end{tabular}

*The entire study period (1984-2006) is considered as pre-BSL implementation period for all jurisdictions that did not implement BSL during our study period.

†95\% Poisson $\mathrm{Cl}$

‡Includes 363 hospitalisations from jurisdictions with no BSL and 144 hospitalisations pre-BSL implementations from jurisdictions with BSL.

§Percentage change in incidence $=-18.1 \%$.

TDifferent at $\mathrm{p}$ value $=0.145$.

**Different at $p$ value $=0.001$ and percentage change in incidence $=-21.5 \%$.

††Different at $p$ value $=0.477$.

$\ddagger \ddagger$ Different at $p$ value $=0.581$

$\S \S$ Different at $p$ value $=0.422$.

ฯ Different at $p$ value $=0.999$.

***Includes 16 jurisdictions with 'pit-bull' specific bans listed in table 1.

BSL, breed-specific legislation.

22 years $(0,95)$, and this was significantly higher than in pre-BSL Manitoba at 11 years $(0,88) \quad(p=0.0007)$. The median (minimum, maximum) age at PEP in post-BSL Manitoba (29.6 $(0.04,97.3)$ years) was higher but by only about 3 years than in pre-BSL Manitoba (26.1 (0.01, 90.4) years; $\mathrm{p}=0.003)$.

Patterns of incidence of DBIH were similar in Manitobans aged $<20$ years as in Manitobans of all ages (table 4). That is, although significant differences were observed at the provincial level when comparing across Manitoba jurisdictions and periods with and without BSL and the percentage change in incidence was $-25.5 \%$, in jurisdictions with BSL there were no significant differences in incidence of hospitalisations between pre-BSL and post-BSL implementation. Again, incidence of PEP increased in the period after BSL implementation in jurisdictions with BSL but was significantly lower when including jurisdictions without BSL in the comparison (see supplementary table 3, available online).

Table 4 Incidence of hospitalised cases of dog-bite injuries in people aged 0 to $<20$ years in the preimplementation and postimplementation period of BSL in the province of Manitoba

\begin{tabular}{|c|c|c|c|c|c|}
\hline & \multicolumn{5}{|c|}{ In people aged $0-<20$ years } \\
\hline & \multicolumn{2}{|c|}{ Preimplementation period of $\mathrm{BSL}^{*}$} & \multicolumn{2}{|c|}{ Postimplementation period of BSL } & \multirow{2}{*}{$\begin{array}{l}\text { p Value of difference } \\
\text { in incidence between } \\
\text { preimplementation and } \\
\text { postimplementation period }\end{array}$} \\
\hline & $\begin{array}{l}\text { Total } \\
\text { Number }\end{array}$ & $\begin{array}{l}\text { Incidence }(95 \% \mathrm{Cl} \dagger) \\
\text { per } 100000 \text { person-years }\end{array}$ & $\begin{array}{l}\text { Total } \\
\text { Number }\end{array}$ & $\begin{array}{l}\text { Incidence }(95 \% \mathrm{Cl} \dagger) \\
\text { per } 100000 \text { person-years }\end{array}$ & \\
\hline All Manitoba jurisdictions & $310 \neq$ & $6.91(6.14$ to 7.68$) \S$ & 157 & $5.15(4.38$ to 6.03$) \S$ & 0.003 \\
\hline $\begin{array}{l}\text { All jurisdictions that did not implement } \\
\text { BSL in the years } 1984-2006\end{array}$ & 226 & $7.09(6.19$ to 8.08$) \Phi^{* *}$ & NA & NA & NA \\
\hline City of Brandon & 14 & $5.26(2.88$ to 8.83$) \dagger † \neq \ddagger$ & NA & NA & NA \\
\hline $\begin{array}{l}\text { All jurisdictions that implemented } \\
\text { BSL sometime during years } 1984-2006 \S \S\end{array}$ & 84 & $6.46(5.15$ to 8.00$)$ & 157 & $5.15(4.38 \text { to } 6.03)^{* *}$ & 0.094 \\
\hline City of Winnipeg & 61 & 5.99 (4.58 to 7.70$) \dagger †$ & 141 & $5.02(4.22$ to 5.92$) \neq \ddagger$ & 0.247 \\
\hline
\end{tabular}

*The entire study period (1984-2006) is considered as pre-BSL implementation period for all jurisdictions that did not implement BSL during our study period.

$+95 \%$ Poisson Cl.

†Includes 226 hospitalisations from jurisdictions with no BSL and 84 hospitalisations pre-BSL implementation from jurisdictions with BSL.

$\S$ Percentage change in incidence $=-25.5 \%$.

बDifferent at $p$ value $=0.469$

**Different at $p$ value $=0.002$ and percentage change in incidence $=-27.4 \%$.

$\dagger+$ Different at $p$ value $=0.663$.

$\neq \neq$ Different at $p$ value $=0.864$.

$\S \S$ Includes 16 jurisdictions with 'pit-bull' specific bans listed in table 1.

$\mathrm{BSL}$, breed-specific legislation.
In the NBR model, hospitalisation RRs of jurisdictions with $\mathrm{BSL}$, relative to jurisdictions without BSL, were not significantly different from one in the period after BSL (table 5). However, relative rates of hospitalisations were significantly lower in urban jurisdictions, represented by Winnipeg and Brandon. In regression restricted to the urban jurisdictions, $\beta$ associated with interaction term between Winnipeg and intervention had a negative sign in model with people of all ages $(\beta=-0.15$; $p<0.0001)$ and with those aged $<20$ years $(\beta=-0.33 ; p<0.0001)$. The rate of DBIH in Winnipeg relative to Brandon was lower in the period after BSL than in the period before BSL in people of all ages (1.10 vs 1.29$)$ and in people $<20$ years of age ( 0.92 vs 1.28$)$ (table 6). Generally, the rate of PEP in Winnipeg was lower relative to Brandon, but higher RRs were observed in the period after BSL than in the period before BSL in people of all ages $(0.76$ vs 0.73 ) and in people $<20$ years of age (0.81 vs 0.66$)$. In other words, while DBIH rate in Winnipeg (relative to Brandon) was 
Table 5 Analysis of dog-bite injury hospitalisations in Manitoba, Canada, 1984-2006*

\begin{tabular}{|c|c|c|c|c|c|c|}
\hline \multirow[b]{2}{*}{ Independent variables } & \multicolumn{3}{|c|}{ Model 1: all ages } & \multicolumn{3}{|c|}{ Model 2: age $<20$ years } \\
\hline & $\bar{\beta}$ & Risk ratio $†(95 \% \mathrm{Cl})$ & p Value & $\bar{\beta}$ & Risk ratio $+(95 \% \mathrm{Cl})$ & p Value \\
\hline $\begin{array}{l}\text { Jurisdiction with BSL versus Jurisdiction } \\
\text { without BSL (before BSL) }\end{array}$ & 0.05 & 1.05 (0.98 to 1.13$)$ & 0.167 & 0.08 & $1.08(1.06$ to 1.10$)$ & $<0.0001$ \\
\hline Urban versus rural $\ddagger$ & -0.33 & $0.72(0.66$ to 0.78$)$ & $<0.0001$ & -0.34 & 0.71 (0.70 to 0.71$)$ & $<0.0001$ \\
\hline
\end{tabular}

*Analysis: negative binomial regression with repeated measures (generalised estimating equations); Dependent variable (continuous)=case count (dog-bite injury hospitalisations) for calendar year per jurisdiction; Offset variable $=\log$ of population count; no. of observations $=414$.

†Denotes magnitude of difference in rate of dog-bite injury hospitalisations associated with each unit increase in explanatory variable when all other variables are held constant.

$\ddagger$ Reference category.

$\mathrm{BSL}$, breed-specific legislation.

lower in the period after BSL than in the period before BSL, rate of PEP was higher in the period after BSL than before.

\section{DISCUSSION}

$\mathrm{DBIH}$ rate in Manitoba was somewhat lower than in the USA (3.9 and 5.1 per 10000 population), ${ }^{46-48}$ Australia (7.7), ${ }^{4} \mathrm{New}$ Zealand $(6.9-7.2)^{49}$ and somewhat higher than in Catalonia, Spain $(1.1-1.8)^{15}$ and previously estimated national-level data in Canada (1.57 and 2.6). ${ }^{50} 51$ When jurisdictions were used as their own controls in a pre-BSL versus post-BSL comparison of incidence of $\mathrm{DBIH}$, no significant reduction in the period after BSL implementation was observed. However, low power to detect an effect may have been an issue. When temporal and geographical variations were introduced in a generalised estimating equations model comparing urban jurisdictions alone, hospitalisation rate in Winnipeg relative to Brandon was lower after BSL. The effectiveness of BSL in decreasing the incidence of DBIH was more pronounced in younger people than in people of all ages.

The impact of BSL on the younger population was specifically studied because medically attended dog bites were reported to affect children younger than 15 years old, especially those 5-9 years old, more so than other age groups. ${ }^{3} 4{ }^{46}$ Children younger than 9 years were reported to be at higher risk of DBIH than were adults. ${ }^{47}$ In this study, due to concerns with small numbers, data were analysed for those $<20$ years old.

Our results support the findings from another populationbased study that a significant decline in DBIH over a 12-year period was associated with stricter government regulations on dog ownership in Catalonia. ${ }^{15}$ Other studies evaluating the impact of dangerous dog regulations (with or without breedspecific clauses) on dog-bite injuries of varying severities in different countries concluded differently. ${ }^{10-14}$ However, data were analysed in a longitudinal, pre/post manner in only two studies $10 \mathrm{12}$; in three studies, researchers employed cross-sectional study designs. ${ }^{11} 1314$ In both longitudinal studies, evaluation was based on shorter periods of observation ( 3 months and 5 years). ${ }^{10} 12$ Also, dog-bite injuries of interest ranged in severity from those not requiring medical attention to those attended to in emergency departments (with a small proportion of the latter requiring hospitalisations). Our finding that DBIH rates are higher in rural areas is also consistent with previous reports. ${ }^{10} 15$

As hypothesised, the pattern observed in the secondary, 'comparison' outcome, namely PEP, was different. The incidence of PEP increased in Winnipeg relative to Brandon in the period after BSL. This was consistent with our expectation that BSL will have little or no impact on PEP received for bites of all severities from all mammals including dogs. If pit-bull type dogs are thought to disproportionately cause serious injuries requiring hospitalisations, then elimination of such dogs was expected to reduce incidence of $\mathrm{DBIH}$ alone and not of PEP.

The empirical setting for the present study included 23 years of population-based data from all Manitoba jurisdictions. Longer periods under observation have the potential to be influenced by period effects or confounding factors such as changes in the number of pet dog populations, changes in the popularity and ubiquity of breeds, changes in number of dog-owning households, parallel and related ordinances, and public safety educational campaigns. While numbers specific to Manitoba are not known, the number of dogs and dog-owning households has been steadily growing in the USA over the years. ${ }^{52} 53$ A higher penetration of dogs in Manitoba households and neighbourhoods could be one reason why a pre/post comparison with potential for confounding from period effects may not have yielded a significant finding. None of these factors were directly accounted for in this study. Instead, we attempted to overcome this problem by comparing with incidence in surrounding communities that may have been subject to the same confounding factors but not to BSL.

Table 6 Analysis of dog-bite injury hospitalisations or rabies post-exposure prophylaxis in urban jurisdictions of Manitoba, Canada, 1984-2006*

\begin{tabular}{|c|c|c|c|c|c|c|c|c|c|c|c|c|}
\hline \multirow[b]{3}{*}{ Independent variables } & \multicolumn{6}{|c|}{ Dog-bite injury hospitalisations (urban Manitoba) } & \multicolumn{6}{|c|}{ Rabies post-exposure prophylaxis (urban Manitoba) } \\
\hline & \multicolumn{3}{|c|}{ Model 1: all ages } & \multicolumn{3}{|c|}{ Model 2: age $<20$ years } & \multicolumn{3}{|c|}{ Model 3: all ages } & \multicolumn{3}{|c|}{ Model 4: age $<20$ years } \\
\hline & $\beta$ & $\begin{array}{l}\text { Risk ratio } \dagger \\
(95 \% \mathrm{CI})\end{array}$ & p Value & $\beta$ & $\begin{array}{l}\text { Risk ratio } \dagger \\
(95 \% \mathrm{CI})\end{array}$ & p Value & $\beta$ & $\begin{array}{l}\text { Risk ratio } \dagger \\
(95 \% \text { CI) }\end{array}$ & p Value & $\beta$ & $\begin{array}{l}\text { Risk ratio } \dagger \\
(95 \% \mathrm{CI})\end{array}$ & p Value \\
\hline $\begin{array}{l}\text { Winnipeg versus } \\
\text { Brandon } \neq \text { (After BSL) }\end{array}$ & 0.10 & $1.10(1.10$ to 1.10$)$ & $<0.0001$ & -0.07 & $0.92(0.92$ to 0.92$)$ & $<0.0001$ & -0.26 & $0.76(0.76$ to 0.76$)$ & $<0.0001$ & -0.21 & $0.81(0.81$ to 0.81$)$ & $<0.0001$ \\
\hline
\end{tabular}

*Analysis: Negative binomial regression with repeated measures (generalised estimating equations); Dependent variable (continuous)=case count (dog-bite injury hospitalisations or rabies post-exposure prophylaxis) for calendar year per jurisdiction; Offset variable $=\log$ of population count; no. of observations $=46$.

†Denotes magnitude of difference in rate of dog-bite injury hospitalisations associated with each unit increase in explanatory variable when all other variables are held constant.

$\neq$ Reference category.

$\mathrm{BSL}$, breed-specific legislation. 
Still, our study has several major limitations. Manitoba jurisdictions were largely grouped together as those with and without BSL. Such a grouping neither considered general heterogeneity within each group nor across the two groups. Enforcement of by-law, known to differ across the different BSL jurisdictions and over the years, was not accounted for in this study. While a specific health outcome such as DBIH was studied with justification, neither the decline in the number of dogs in the banned breeds nor the proportion of DBIH that can be attributed to the banned breed have been determined. Other differences between jurisdictions with and without BSL have the potential to influence the study results. As quasi-experimental study designs can inform discussions of cause and effect but cannot definitely establish a link, the results of our finding should be interpreted cautiously. ${ }^{33}$

Similarly, as the proportion of PEP attributed to dog bites of varying severities is not known, our use of PEP as a comparative outcome may have limited value. While the primary reservoir of rabies in Manitoba is the striped skunk, spillover into domestic animals has been established. ${ }^{54}$ Among 512 animals submitted for rabies testing and diagnosis from Manitoba in 2006, 139 (27.1\%) were dogs. ${ }^{56}$ In 17 jurisdictions in the USA in 2006, $33 \%$ (range: $8 \%$ to $82 \%$ ) of PEP was for exposure to dogs. ${ }^{24}$ In Pennsylvania in 1995, 30\% of PEP was for exposure to dogs. ${ }^{23}$ Therefore, we tentatively estimate that no less than $30 \%$ of the PEP reported in this study may be attributed to dog bites, although it could be much higher than that. Dogs account for $80 \%$ to $90 \%$ of all bites injuries in humans. ${ }^{57}$ Still, the proportion of PEP attributed to dog bites versus other mammalian bites, expected to vary across geography and time in Manitoba, remains unknown here. Also, some PEP could be attributed to bites from banned breeds and if this proportion is large enough we would theoretically expect the incidence of PEP to also be effected by BSL, contrary to assumptions made here. Our aim to demonstrate that BSL has little effect on incidence of PEP was achieved within the context of such data limitations and uncertainties in assumptions. Perhaps a more ideal comparative outcome for the purposes of this study would be dog bites of all severities. However, such data were not available to us.

In addition, although care was taken through different avenues to identify all major jurisdictions that implemented BSL, the possibility of misclassification of a small municipality with current or past BSL as a control jurisdiction in the study cannot be ruled out. However, any residual misclassification is expected to affect only a small proportion of Manitoba's population as classification of the 15 largest jurisdictions was carefully verified.

In conclusion, the strengths of the present study include use of population-based data, assessment of longer-term effective-

\section{What is already known on this subject}

- Few studies have employed longitudinal data analytic methods in the area of dog-bite injuries.

- Fewer studies have assessed the effectiveness of dog-control legislation in decreasing the number of hospitalizations due to dog-bite injuries in people.

- Breed-specific legislation is an area of considerable controversy that would benefit from long-term evaluation studies in which data from surrounding unlegislated areas are used for comparative purposes.

\section{What this study adds}

When jurisdictions were used as their own controls in a pre/ post comparison of incidence of dog-bite injury hospitalisations, no significant reduction in incidence was observed in the period after breed-specific legislation (BSL) was implemented.

- When temporal and geographical variations were introduced in a generalised estimating equations model comparing urban jurisdictions alone, hospitalisation rate in Winnipeg (city with $\mathrm{BSL}$ ) relative to Brandon (city without BSL) was lower after implementation of legislation.

- The effectiveness of BSL in decreasing the incidence of dogbite injury hospitalisations was more pronounced in younger people than in people of all ages.

ness, adjustment for temporal, period and geographic effects, and appropriateness of the model selected to study count data, namely NBR. Despite the study limitations listed, trends in population-level outcomes studied collectively suggest that BSL in Manitoba may have decreased DBIH in people, especially in those younger than 20 years. Our study adds to the limited body of evaluation literature that shows a decline in $\mathrm{DBIH}$ as a result of government regulation.

Acknowledgements The authors acknowledge the Manitoba Centre for Health Policy for use of data contained in the Population Health Research Data repository under project number (HIPC number: 2009/2010-08). The results and the conclusions are those of the authors and no official endorsement by the Manitoba Centre for Health Policy, Manitoba Health, or other data provider is intended or should be inferred

Contributors MR: study design, data assembly, model specification, data analysis, interpretation of data and models, writing and editing of the manuscript, final approval of the version to be published. PJM: obtained funding, administrative, technical and material support and supervision, interpretation of data and models, editing of manuscript and final approval of the version to be published. DC: contributed statistical expertise, model specification and interpretation, final approval of the version to be published. CB: data assembly, administrative and technical support including mapping, interpretation of data, final approval of the version to be published

Funding This study was made possible by funding from the CIHR/PHAC Applied Public Health Chair Award (2007-2012) to PJM.

\section{Competing interests None.}

Ethics approval Ethics approval was provided by Manitoba Health Information Privacy Committee and University of Manitoba Health Research Ethics Board.

Provenance and peer review Not commissioned; externally peer reviewed.

Data sharing statement The dataset created for the purpose of this analytical study is available from MR. Almost all the analyses performed are presented in the manuscript.

Open Access This is an Open Access article distributed in accordance with the Creative Commons Attribution Non Commercial (CC BY-NC 3.0) license, which permits others to distribute, remix, adapt, build upon this work non-commercially, and license their derivative works on different terms, provided the original work is properly cited and the use is non-commercial. See: http://creativecommons.org/licenses/by-nc/3.0/

\section{REFERENCES}

1. Presutti RJ. Prevention and treatment of dog bites. Am Fam Physician 2001;63:1567-72.

2. Gilchrist J, Sacks JJ, White D, et al. Dog bites: still a problem? Inj Prev 2008;14:296-301.

3. Overall KL, Love M. Dog bites to humans-demography, epidemiology, injury, and risk. J Am Vet Med Assoc 2001;218:1923-34

4. Ozanne-Smith J, Ashby K, Stathakis VZ. Dog bite and injury prevention-analysis, critical review, and research agenda. Inj Prev 2001;7:321-6. 
5. CBC News/CBC Marketplace. 'Dangerous dog' bylaws Across Canada. http:// www.cbc.ca/marketplace/pre-2007/files/health/dangerousdogs/bylaws.html (accessed 15 Feb 2012).

6. Straka A. Vancouver City Council: Agendas, Reports, Minutes. Dangerous Dogs: Protection Strategy. http://vancouver.ca/ctyclerk/cclerk/20050217/pe2.htm (accessed 15 Feb 2012).

7. Ledger RA, Orihel JS, Clarke N, et al. Breed specific legislation: considerations for evaluating its effectiveness and recommendations for alternatives. Can Vet $J$ 2005:46:735-43.

8. AVMA Task Force on Canine Aggression and Human-Canine Interactions. A community approach to dog bite prevention. J Am Vet Med Assoc 2001:218:1732-49.

9. Burstein D. Breed specific legislation: unfair prejudice and ineffective policy. Animal Law 2004:10:313-61.

10. Rosado B, Garcia-Belenguer S, Leon M, et al. Spanish dangerous animals act: effect on the epidemiology of dog bites. J Vet Behav 2007;2:166-74.

11. Cornelissen JM, Hopster H. Dog bites in The Netherlands: a study of victims, injuries, circumstances and aggressors to support evaluation of breed specific legislation. Vet J 2010;186:292-8.

12. Klaassen B, Buckley JR, Esmail A. Does the dangerous dogs act protect against animal attacks: a prospective study of mammalian bites in the accident and emergency department. Injury 1996;27:89-91.

13. Bandow JH. Will breed-specific legislation reduce dog-bites? Can Vet $J$ 1996;37:478-81

14. De Keuster D, Lamoureux J, Kahn A. Epidemiology of dog bites: a Belgian experience of canine behavior and public health concerns. Vet J 2006;172:482-7.

15. Villalbi JR, Cleries M, Bouis S, et al. Decline in hospitalisations due to dog bite injuries in Catalonia, 1997-2008. An effect of government regulation? Inj Prev 2010;16:408-10.

16. City of Winnipeg. By-law no. 2443/79. The Pound By-Law. 17 October 1979. http:// www. winnipeg.ca/CLKDMIS/DocExt/ViewDoc.asp?DocumentTypeld=1\&Docld=428 (accessed 31 Jan 2012).

17. Rural Municipality of Macdonald, By-Law no. 15/09. Dog by-law. 9 June 2009.

18. City of Thompson. By-Law No. 1500-994. Dog licensing and animal control bylaw. 26 September 1994

19. Hess G. Pro canine breed-specific legislation. Can Vet J 1996;37:712

20. Shuler CM, DeBess EE, Lapidus JA, et al. Canine and human factors related to dog bite injuries. J Am Vet Med Assoc 2008;232:542-6.

21. Bini JK, Cohn SM, Acosta SM, et al. Mortality, mauling, and maiming by vicious dogs. Ann Surg 2011;253:791-7.

22. Grill AK. Approach to management of suspected rabies exposures: what primary care physicians need to know. Can Fam Physician 2009:55:247-51.

23. Moore DA, Sischo WM, Hunter A, et al. Animal bite epidemiology and surveillance for rabies postexposure prophylaxis. J Am Vet Med Assoc 2000;217:190-4.

24. Christian KA, Blanton JD, Auslander M, et al. Epidemiology of rabies postexposure prophylaxis-United States of America, 2006-2008. Vaccine 2009;27:7156-61

25. Manitoba Health Communicable Disease Control. Protocol for Management of Animal Exposures to Prevent Human Rabies. 2006. http://www.gov.mb.ca/health/ publichealth/cdc/protocol/rabies_protocol.pdf (accessed 29 Jan 2012).

26. Blanton JD, Bowden NY, Eidson M, et al. Rabies postexposure prophylaxis, New York, 1995-2000. Emerg Infect Dis 2005:11:1921-7.

27. Concept: Urban/Rural Definitions. Concept Description. http://mchp-appserv.cpe. umanitoba.ca/viewConcept.php?printer $=$ Y\&conceptID=1253 laccessed 29 Feb 2012).

28. Manitoba Centre for Health Policy. Population Health Research Data Repository http://umanitoba.ca.proxy1.lib.umanitoba.ca/faculties/medicine/units/ community_health_sciences/departmental_units/mchp/resources/repository/index. html (accessed 2 Mar 2011).

29. World Health Organization. International Classification of Diseases. http://www. who.int/classifications/icd/en/ (accessed 2 Mar 2011).

30. Last JM. A Dictionary of Epidemiology. 3rd edn. New York: Oxford University Press, 1995.

31. Texas Department of State Health Services. Report of Birth Defects Among the 1999-2008 deliveries. http://www.dshs.state.tx.us/birthdefects/data/BD Data 99 08/Report-of-Birth-Defects-Among-1999-2008-Deliveries/ (accessed 29 Jan 2012).
32. Langlois P. Boost your confidence intervals with SAS. Proceedings of the 2010 Meeting of the South Central SAS Users Group. http://www.scsug.org/ SCSUGProceedings/2010/Langlois/Langlois conf intervals for SCSUG Educ Forum.pdf (accessed 29 Jan 2012).

33. Treasury Board of Canada Secretariat. Program evaluation methods Measurement and Attribution of program results 3rd edition. Minister of Public Works and Government Services Public Affairs Branch, 1998. http://www.tbs-sct.gc.ca/cee/ pubs/meth/pem-mep-eng.pdf (accessed 29 Jan 2012).

34. Taleff MJ. The quasi-experimental Method. Research to Practice. Counselor. 1999 http://www.counselormagazine.com/columns-mainmenu-55/48-research-topractice/471-the-quasi-experimental-method (accessed 29 Jan 2012)

35. Moore KA. Quasi-experimental evaluations. Practical Evaluation Methods. Child Trends. Washington, DC: The Atlantic Philanthropies, 2008. http://www.childtrends. org/Files/Child Trends-2008 0116 Evaluation6.pdf (accessed 29 Jan 2012).

36. Camden A, Büliung $R$, Rothman $\bar{L}$, et al. The impact of pedestrian countdown signals on pedestrian-motor vehicle collisions: a quasi-experimental study. Inj Prev. Published Online First: 25 February 2012. doi:10.1136/injuryprev-2011-040173

37. Gardner W, Mulvey EP, Shaw EC. Regression analyses of counts and rates: Poisson, overdispersed Poisson, and negative binomial models. Psychol Bull 1995;118:392-404.

38. Chang LY. Analysis of freeway accident frequencies: negative binomial regression versus artificial neural network. Saf Sci 2005;43:541-57.

39. McDonald TL, Erickson WP, McDonald LL. Analysis of count data from before-after control-impact studies. J Agric Biol Envir Stat 2000;5:262-79.

40. Pedan A. Analysis of Count Data Using the SAS System. Statistics, Data Analysis, and Data Mining (Paper 247-26). http://www2.sas.com/proceedings/sugi26/p24726.pdf (accessed 29 Jan 2012).

41. Negative binomial regression. UCLA: Academic Technology Services, Statistical Consulting Services, Statistical Consulting Group. http://www.ats.ucla.edu/stat/stata/ output/stata nbreg output.htm (accessed 29 Jan 2012).

42. Nichols DP. Using categorical variables in regression. UCLA Academic Technology Services. Statistical Consulting Group. 1995. http://www.ats.ucla.edu/stat/spss/ library/catreg.htm (accessed 31 Jan 2012).

43. Proc Genmod. Cary, NC: SAS Institue, Inc, 2008

44. SAS Institute Inc. SAS/STAT User's Guide, Version 9.2. Cary, NC: SAS Institute Inc., 1999.

45. City of Brandon. By-Law no. 5900/57/91. Animal control by-law. 17 June 1991.

46. Weiss HB, Friedman DI, Coben $\mathrm{JH}$. Incidence of dog bite injuries treated in emergency departments. JAMA 1998;279:51-3

47. Castrodale L. Hospitalizations resulting from dog bite injuries-Alaska, 1991-2002 Int J Circumpolar Health 2007:66:320-7.

48. Quinlan KP, Sacks JJ. Hospitalizations for dog bite injuries. JAMA 1999;281:232-3

49. Marsh L, Langley J, Gauld R. Dog bite injuries. N Z Med J 2004;117:1043-9.

50. Flores J, Brown J, Mackenzie SG, et al. Innovative CHIRPP project focuses on dog bites. CHIRPP News 1997;11:3-7.

51. Health Surveillance and Epidemiology Division (Public Health Agency of Canada). Injuries associated with non-fatal dog bites: Canadian Hospitals Injury Reporting and Prevention program (CHIRPP) database, 1990-2003 (cumulative to January 2005). All ages, 13,921 records, http://www.phac-aspc.gc.ca/injury-bles/ chirpp/pdf/CHIRPP INJURY BRIEF DOG BITE update.pdf (accessed 20 Jun 2012).

52. Shepherd AJ. Results of the $200 \overline{6}$ AVMA survey of companion animal ownership in US pet-owning households. J Am Vet Med Assoc 2008:232:695-6.

53. PRWeb. New survey reveals pet ownership at its highest level in two decades and pet owners are willing to pay when it comes to pet's health. American Pet Products Association Press Release, Greenwich, CT (Vocus/PRWEb) April 04, 2011. http:// www.prweb.com/releases/2011/4/prweb8252684.htm (accessed 2 Feb 2012)

54. Kush J, Prins S, Olson W. Rabies diagnosis in western Canada, January 1 to June 30, 1995. Can Vet J 1995;36:776.

55. Prins B, Loewen KG. Rabies diagnosis in western Canada, 1985-1989. Can Vet $J$ 1991;32:487-91

56. Fehlner-Gardiner C, Muldoon F, Nadin-Davis S, et al. Laboratory diagnosis of rabies in Canada for calendar year 2006. Can Vet J 2008:49:359-61.

57. Griego RD, Rosen T, Orengo IF, et al. Dog, cat, and human bites: a review. J Am Acad Dermatol 1995;33:1019-29. 